\title{
Study on the Role of Audit Archives Management in Audit Quality Work
}

\author{
Yun $\mathrm{Hu}$ \\ Qilu Normal University \\ (Shandong,China 250013)
}

Keywords: Audit quality; Archives management; Role

\begin{abstract}
The auditing organ plays an irreplaceable role in promoting national economic development level, and archives management as an important part of audit quality work to provide the basis, effectively reflects the real efficiency and quality of audit work. In this paper, it starts from the main characteristics of the audit archives, the role of the audit archives and how to further enhance its role in the audit quality work are discussed briefly.

The normal operation of the auditing organ is an important prerequisite to ensure the effectiveness of national economic order, and audit archives can provide key evidence for audit quality, so the management of audit archives quality is directly related to the risk assessment and prediction and audit quality work problems.
\end{abstract}

\section{Main Characteristics of Audit Archives}

As a direct presentation of the audit work process and results, audit archives have many typical characteristics including the following aspects:

The impartiality of audit archives. The reason of audit records can provide important evidence for the follow-up audit work, and later become the cornerstone of audit risk prevention, effective prediction and assessment of risk, mainly the impartiality of the audit archives. Audit archives are often in the audit process in the past, after the audit audit results by the authoritative audit unit according to the legal procedures, both the process and conclusion have objectivity and impartiality, so the audit archives mean the existence of a maximum value which is also relying on legal effectiveness audit contribution after the fairness for certain. Therefore, in the audit work, the relevant units must provide a relatively perfect and absolutely authentic audit materials.

Professional and particularity of audit archives. With the particularity of audit supervision, as a record and fully reflect the audit supervision process and the results of the audit archives, they also have a high degree of professionalism and particularity. Audit documents in the record, sorting,filing, inspection process must be strictly in accordance with the audit process and related regulations, the professional degree and particularity based on the audit regulations are guaranteed with prove certain.

Continuity and relevance of audit archives. Audit archives means the record of the audit process and results, and audit process is divided into three steps: the first is to determine the audit object, audit object according to the audit plan drawn up in advance and the establishment of the audit group; the second is to determine the audit object issued after the audit notice, in strict accordance with legal procedures and audit the originally proposed audit project implementation audit behavior, and write audit report according to the audit process and results of the audit report; the third is proposed for final approval and approval according to the examination results of opinions and suggestions are given on the object and node. All the steps are continuous, and the audit process involved in the audit report of all materials, and documents should also be in accordance with the correct sequence file as audit archives, therefore, it should be according to the audit which also have continuity and relevance.

\section{Role of Audit Archives Management}

The fairness, professionalism and particularity of audit records, continuity and relevance of such features marked the close relationship between the supervision and audit, through the audit and supervision of activities authentic, and the complete and detailed records of the audit records 
effectively reflect the actual effect and results of auditing work. With the continuous improvement of the status of audit in the national economic development, the role played by the audit archives is increasingly obvious and prominent. From another point of view, the audit archives also represent and reflect the role of the audit institutions to promote the construction of leading cadres.

A large amount of audit information. The audit archives include not only the paper material, with the increasingly advanced technology, audio, video, pictures and other materials have been incorporated into the audit archives arrangement, it fully reflects the inclusive strong and full of audit archives, characteristics of large capacity, comprehensive make audit archives become the important carrier of information storage of audit supervision. And based on the stored management of audit archives, it can ensure the integrity of the original audit data, minimizing audit material deficiencies, omissions and distortion, and reasonable properly preserved also implements the principles of confidentiality, which realize the audit process and conclusion to a certain extent, at the same time, the information stored is convenient for later access and browsing.

Audit archives provide evidence for the audit supervision. In the process of audit supervision, if someone wants to improve audit quality, it must guarantee the seriousness and fairness, each of the steps means the selection and preparation of the audit materials determines the quality of audit or not. Audit is the premise of existence in fact, so whether it is for the preliminary audit object and later review, audit archives can be used as materials and evidence of the authority of the audit results are confirmed or provide a favorable basis for the corresponding. In the reality of the audit work in every aspect, the audit materials are real as the most basic criteria were recorded, so in order to consider the entire audit process justice and reproduce the historical reality, the audit material should be recorded as evidence preserved.

Audit archives is effective tool to evaluate the effectiveness of audit work. As the saying goes "a good memory is better than a bad pen". Comprehensive evaluation of the audit process if someone wants to have formed or has occurred, only by the audit staff of the oral narrative based on memory is clearly not practical, so to further summarize or evaluate the vast extent which will depend on the effectiveness of audit archives on the audit work, taking this way on the one hand is to avoid the information incomplete and inaccurate, and on the other hand is the guarantee of the previous audit staff work respect to ensure the objectivity of the evaluation of the past that be able to audit a realistic reduction, comparison and evaluation. According to the relevant audit activities in recent years in the country to carry out the game project, audit file is almost the only basis for the score, and it is sufficient to prove that the audit archives plays an important role in the work place.

Audit archives provides materials on the national audit propaganda. The audit archives of large capacity and a wide range of information inclusive and audit supervision of the particularity of it stored in the content of a large number of replacement and national economic benefit, economic law and economic policy related information, audit archives and carries on the reasonable use of publicity, not only to the effectiveness of leading cadres and staff the public that the audit work carried out, but also in a more transparent than the other ways existing to make people understand the national economic policies and economic means, to a certain extent, it can help provide greater role for economic development and the promotion of social stability and market.

\section{Measures for Improving the Audit Archives Management}

In the understanding of the importance of audit archives in audit quality work, in order to give full play to the important role of audit archives work, it must be in the background of rapid development of economy, culture, science and technology and other social sectors to further upgrade the quality and efficiency of audit management work.

To improve the overall quality of audit archives management staff. The overall quality of the archives management staff is directly related to the quality of the audit archives management, but also related to the normal audit process. The personnel archives management level mainly includes two aspects: one is the professional level to ensure the integrity of the material which related to regular business training for staff, ensure the archiving and preservation of materials to the professional level. And the other is the moral level and occupation ethics ascension archives 
management, humanistic quality and the occupation ethics can make archives management personnel shall undertake audit archives responsibility strictly to ensure fair and objective archives. In addition, the relevant requirements of the audit archives management can be seen as as an ergonomic evaluation system and staff monthly, quarterly, annual assessment and other direct linked to enhance their enthusiasm for work.

Further improve the archives management system and process. The system of archives management including data collation, induction, preservation, transmission machine and so on, in each item, it must ensure that the paper and electronic versions of materials for processing should be intact, separately for different processes, the implementation of auditing materials and avoid confusion. At the same time, in order to ensure the seriousness and authority of audit archives, it must establish relevant laws and regulations, and the relevant units can also develop in line with their business needs regulations and standardize audit procedures to make audit evaluation more accurate, archives on the more authentic and detailed and complete, and the file extraction storage is more secure, to avoid the artificial interference and tampered with or damaged documents and information. To perfect the system and process of archives management is an important premise to promote the scientific, standardized and legalized archives management.

To strengthen the consciousness of audit archives management. The increasing level of technology makes the audit material properties are more and more diversified, and about the relevant management consciousness but not in time to keep up with the pace of development, related to the audit organs and units of audit archives management consciousness and the idea are still in the traditional means, so as to enhance the efficiency of auditing in some male audit process, which is extremely easy to cause the loss of audit file. To strengthen the management of audit archives consciousness shaping help to further strengthen the people pay attention to the audit work, the audit quality of work related grasp the key link of file management, so as to effectively improve the quality and effect of archives management.

The introduction of modern science and technology to assist the management of audit archives. The popularity of Internet technology provides more possibility and convenience for the archives management institutions and enterprises, and audit archives management should be referred as soon as possible the introduction of cutting-edge science and technology making archives management more scientific and university. In the aspect of data storage, it can reduce unnecessary loss, and can save a certain amount of labor management cost. The data and information audit materials also put forward new requirements for the management of audit archives. But it is worth noting that, although the Internet technology to archives management has brought a lot of convenience, it also has a certain risk, and some hackers can damage and malicious tampering of data using the network, so the security but also to strengthen the protection of archives.

\section{Conclusion}

Audit archives is an important part of the national archives, and archives management should also be used as the daily work of the audit organs and units, not only to strengthen the audit process and result fairness and evaluation of the seriousness and authority, but also attaches great importance to the audit of the archives management work to ensure that no danger of anything going wrong. Audit practice is the most basic premise of audit records, if it can not guarantee the authenticity of the audit practice, save the audit files and other related operations will be a mere formality, which means it unable to play its due role. The status of audit work to enhance the role of the audit file began to show, and it is also necessary to ensure the vigorous development of audit work.

\section{References}

[1] [1]Lei Li, Haidong Wang.Continuous auditing is an effective way to improve audit quality[J].Communications Enterprise Management.2012(11). 
[2] [2]Lu Han, Yiqun Zhao.The position and function of audit archives management in audit quality[J].Modern Communication.2013(11).

[3] [3]Xiaoxia Li, Minghui Li.The effect of merger on audit quality- Empirical Evidence from Chinese capital market[A].Proceedings of the twenty-fifth Symposium on financial cost of China Accounting Association[C].2012. 